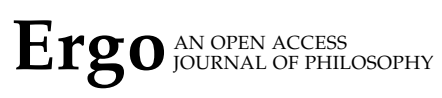

\title{
Constructing Contexts
}

\author{
BRETT SHERMAN \\ University of Rochester
}

\begin{abstract}
It is commonly held that the context with respect to which an indexical is interpreted is determined independently of the interpretation of the indexical. This view, which I call Context Realism, has explanatory significance: it is because the context is what it is that an indexical refers to what it does. In this paper, I provide an argument against Context Realism. I then develop an alternative that I call Context Constructivism, according to which indexicals are defined not in terms of features of utterance situations, but rather in terms of roles that objects could play.
\end{abstract}

$\mathrm{L}$

INGUISTIC context-dependence is messy and complicated, but indexicality is supposed to be the bit of it that we understand well. On the standard picture, each indexical is defined in terms of some contextual feature; the correct interpretation of a use of an indexical is explained by whichever object has the relevant feature in the context in which it is used. I argue here that this account of the relationship between context and indexical interpretation gets the explanatory order wrong, and I propose an alternative account. I begin with a puzzle aimed at uncovering a consequence of the standard explanatory picture concerning patterns of counterfactual dependence, patterns that are in tension with the puzzle.

\section{A Puzzle about Indexical Choice}

Ever since my popularity skyrocketed, membership in my online social network has become an extremely desirable goal for many to achieve. In order to maintain some semblance of exclusivity, I have decided to restrict membership to those who are related to me in some arbitrary manner. Here are two ways that I might proceed.

Option 1: I choose to restrict membership to those who know me personally. And so I announce that anyone who wishes to join my social network will be asked to provide evidence that they know where I live.

Contact: Brett Sherman <brett.sherman@rochester.edu> 
Option 2: I choose to restrict membership to those who reside in the same town as me. And so I announce that anyone who wishes to join my social network will be asked to provide evidence of the town in which they reside.

Regardless of which option I choose, the means for gathering the evidence is the same. Whenever a membership request is made, a screen appears containing the phrase My Zip Code to the left of a small text box in which the viewer of the site can enter a Zip Code. If there is a match, the membership is granted.

On the assumption that each applicant answers truthfully, whose Zip Code does the applicant enter: mine or theirs? The answer is that it depends on which option I choose. If I take the first option, wherein I announce that I require evidence that an applicant knows where I live (perhaps this is written on the Zip Code entry screen), then the only way that I will get the desired evidence is if the ' $m y^{\prime}$ in My Zip Code refers to me. If I take the second option, wherein I announce that I require evidence about where an applicant lives, then the only way that I will get the desired evidence is if the 'my' in My Zip Code refers to the applicant.

That the indexical 'my' can refer to different people in different contexts is hardly surprising or puzzling. However, a puzzle emerges when we seek to explain why the indexical is interpreted as it is. The standard explanation appeals to the way that the fixed meaning of the indexical-its character, according to David Kaplan (1989a) - fits together with the context in which it is used. According to this story, the character of ' $m y^{\prime}$ ' is associated with a particular contextual feature, specifically the feature of being the speaker of the context. Whichever object has that feature in a particular context of use thereby becomes the referent of 'my' relative to that context. When ' $m y^{\prime}$ is used, it is as if the indexical scans the context of use to find whoever is the speaker of the context, plucking the object up and making it the referent.

On the standard picture, there are differences between Option 1 and Option 2 , and those differences result in different contexts. The resulting contexts differ with respect to which objects have which features. If I choose Option 1, then when the Zip Code entry screen appears, the speaker of the context is me. If I choose Option 2, then the speaker of the context is the applicant.

However, as an explanation for why the indexical ' $m y^{\prime}$ is interpreted as it is, this account runs into a problem. To see what the problem is, consider the context that results from my taking Option 1. According to the standard account, the speaker of the context is me and the addressee of the context is the applicant. It follows that, in this context, if I had instead used the indexical 'your', whose character picks out the addressee of the context, then the indexical would have picked out the applicant. But that prediction is not borne out. If I were to alter the Zip Code entry screen to use the phrase Your Zip Code, the indexical 'your' would pick out me rather than the applicant. 
A similar result obtains for the context that results from taking Option 2. According to the standard account, the speaker of the context is the applicant, and the addressee of the context is me. But were I to substitute the phrase Your Zip Code in this context, the indexical 'your' would still pick out the applicant. There is something puzzling about this. We should expect that, relative to a given context, indexicals that are sensitive to distinct parameters of the context would pick out distinct individuals. Yet, in both of the situations considered, the interpretation of 'my' and 'your' would be the same; what would change is who counts as the speaker and who counts as the addressee. Why does that happen? Why are we able to choose which of 'my' and 'your' to use? That is the puzzle. ${ }^{1}$

The puzzle might seem to rely on the technological aspects of the example, in a way that lessens its significance for our understanding of indexicality. One might imagine, for example, that any occurrence of an indexical on a website can give rise to the same effect whereby swapping one indexical for another would change, not the interpretation, but the contextual parameters. However, things are not this simple. Some uses of indexicals on websites do not give rise to a swapping effect.

Suppose, for example, that I used the phrase Please enter my Zip Code on the Zip Code entry site. It would not be possible to swap 'my' with 'your' in this phrase without changing the interpretation. This fact, by itself, does not tell us anything about the source of the puzzle. But it suggests that hand-waving toward the technological features of the puzzling example, by itself, won't suffice. There are substantial interpretive facts calling out for explanation. Given that swapping the 'my' with 'your' in Please enter my Zip Code would change the interpretation and not the contextual parameters, why would swapping the 'my' with 'your' in My Zip Code change the contextual parameters thereby preserving the interpretation?

To be clear, the puzzle is not to explain why Please enter my Zip Code is interpreted as it is. That is an interesting question, one that I return to in Section 4. The imperative mood seems to play an important role, a factor which the standard approach can also appeal to. The puzzle is not concerned with the cases in which we cannot switch between 'my' and 'your'; the puzzle is that there are cases in which we can switch. I raise the Please enter my Zip Code example in order to show that the switching is not a trivial consequence of the indexical appearing on a website.

1. For real examples similar to the Option 2 scenario, readers are invited to visit two archived websites, which can be found at http://www.tinyurl.com/constructingcontexts 1 and http://www.tinyurl.com/constructingcontexts2 exhibiting uses of My Zip Code and Your Zip Code respectively. For pragmatic reasons, it is difficult to find real examples similar to the Option I scenario (that is, where the indexicals pick out the author of the website). But note the use of 'we' in the first question below the Zip Code entry box in the first website linked. 
More importantly, the puzzle is not simply to come up with an explanation for why My Zip Code and Your Zip Code are interpreted as they are. Insofar as we do interpret these phrases, there must be some explanation for why we so interpret them. I do not deny that. The puzzle is to come up with an explanation that also allows for the fact that we can choose between 'my' and 'your'.

It is this puzzle that, I argue, poses a significant problem for a widely-held view about indexicals and context that I call Context Realism. Context Realism is the view that the character of an indexical is defined in terms of some contextual feature that an object has independent of, or prior to, the interpretation of the indexical. This view is exhibited by the standard explanation, considered above, of why indexicals are so interpreted, according to which the indexical scans, as it were, for whichever object has the relevant contextual feature. The following passage by Robert Brandom (2008) provides a recent explicit articulation of the view:

What I want to call 'genuine' semantic indices are features of utterances that can be read off without knowing anything about what the utterance means. Time, place, speaker, and possible world are properties of tokenings that can be settled and specified before one turns one's attention to the content expressed by those tokenings. (Brandom, 2008, 58).

This concept of a 'genuine' semantic index is directly tied to the explanatory role that these indices are thought to play: it is because the utterance features are what they are that the corresponding indexical refers to what it does.

In this paper, I argue that there are no 'genuine' semantic indices in Brandom's sense. This is not to say that utterances do not have features that can be settled and specified independently of the interpretation of the utterance. Rather, it is to say that the characters of indexicals are not built out of such features; the features aren't semantically relevant in the way that the Context Realist supposes. Here I present and defend an alternative view about indexicals and context that I call Context Constructivism. According to Context Constructivism, the character of an indexical is defined in terms of a particular kind of constructed property.

An example will help to make the idea clearer. There is a difference, I claim, between the property of being the speaker and the property of counting as the speaker. One can have the property of being the speaker of a particular utterance independently of the interpretation of the uttered sentence. However, the property of counting as the speaker is different. It is more like a role that someone can play. ${ }^{2}$ I argue here that interpreting the indexical amounts to determiningmaking it the case-who counts as the speaker, or who plays the speaker role.

2. Fillmore (1997), Goffman (1974), McCawley (1999), Perry (2006), and Récanati (in press) have all appealed to some notion of role in giving an account of the fixed meanings of indexicals. 
As a result, a theoretical shift from objective features to constructed propertiesfrom Context Realism to Context Constructivism-has significant explanatory implications. The twin goals of the paper are to argue that the characters of indexicals are defined in terms of these 'counting as' properties-roles that objects could play rather than real features of utterances-and to examine how the resulting Constructivist conception of context works.

Before continuing, a couple of preliminary remarks are in order. First, although the Brandom quote may obscure this point, the distinction between socalled "pure" and "impure" indexicals is orthogonal to the issue separating the Realist and the Constructivist. Kaplan originally defined pure indexicals as those for which "no associated demonstration is required, and any demonstration supplied is either for emphasis or is irrelevant" (Kaplan, 1989a, 491). In light of subsequent work by Kaplan, among others, a distinction is now more commonly drawn between those indexicals whose reference is fixed in part by the speaker's intention and those that are not. ${ }^{3}$

Now, suppose that I say to you, "The weather is lovely this time of year." My intention to speak to you is what makes you the addressee. That you are the addressee is a feature of the utterance that holds independently of the interpretation of the sentence uttered. At issue between the Realist and the Constructivist is the question whether a use of 'you' is defined in terms of this contextual feature of being the addressee, the instantiation of which is determined independently of the interpretation of 'you', or whether it is defined in terms of a role-the property of counting as the addressee-the instantiation of which, I argue below, is not determined independently of the interpretation of 'you'. Whether speaker intentions are needed to fix who has the feature in question is beside the point.

The second preliminary remark concerns the use of the term 'context'. As the quote from Brandom makes clear, the term 'index' has been used for something like what I am calling the context. ${ }^{4}$ The term 'context' is one of those unfortunate theoretical terms that has pre-theoretical uses (as in, 'taking things out of context') as well as a number of distinct theoretical uses. Among other uses, we can speak of the context as the (plainly real) situation in which an utterance takes place, the object that conversational speech acts aim to update, or the object relative to which an indexical has a content. ${ }^{5}$

3. See, for example, Kaplan (1989b) and Bach (1992) for accounts in terms of speaker intentions. Perry (1997) contains a useful discussion of the distinction. In addition to distinguishing what he calls 'automatic' from 'intentional' indexicals, Perry further distinguishes between those that are defined in terms of wide and narrow features of the context. According to Perry, it is the narrow-automatic indexicals that are "pure".

4. Recent uses of 'index' along these lines can be found in Lewis (1980) and Predelli (2005).

5. For example, see Lewis (1980) for the first use, Stalnaker (1998), Roberts (2012), and Murray (2014) for the second use, and Kaplan (1989a) for the third use. 
It is an open question whether these distinct theoretical uses pick out the same object. The term 'index' has traditionally been used to pick out the object relative to which an indexical has a content. And it is typically held that every utterance situation is associated with some particular index. If this last claim is correct, then there is little harm in speaking of an indexical having a content relative to a context without distinguishing which concept of context is at issue.

However, it is this claim-that every utterance situation is associated with some particular index-that I challenge here. I argue that we cannot simply read off from a particular utterance situation what the index of that situation is-what the sequence of semantically relevant properties is-apart from interpreting the utterance. So why not speak of 'Index Realism' and 'Index Constructivism'? The reason is simple. It is a sociological fact about present-day philosophers that they are unwilling to give up the claim that indexicals (and expressions more generally) have a content relative to a context. Despite whatever other uses it has, the term 'context' is firmly entrenched as picking out whatever expressions have a content relative to. I am happy to play along. The question, then, is whether contexts-the sorts of things that expressions have contents relative toare determined independently of, or prior to, the interpretation of sentences. The Realist says yes, the Constructivist, no.

Ultimately, I argue that Context Constructivism is capable of explaining the sorts of facts that are standardly thought to motivate Context Realism, along with the facts that Context Realism is unable to account for. To argue this, I develop (in Section 4) a broadly Gricean pragmatic framework that imposes constraints on how we interpret indexicals. However, I begin (in Section 2) by presenting an argument against Context Realism.

\section{Features, Roles, and Counterfactual Dependence}

My argument against Context Realism is of Modus Tollens form. I argue that if Context Realism were true, then all counterfactuals of a certain sort would be true. But some of those counterfactuals are false. Therefore, Context Realism is false. The example with which this paper began is intended to provide support for the second premise. When I choose Option 1 in the above example, the expression 'My Zip Code' refers to my Zip Code; but it is not the case that, had the expression 'Your Zip Code' been used instead, it would have picked out the applicant's Zip Code. Likewise with Option 2: it is not the case that, had the expression 'Your Zip Code' been used, it would have picked out my Zip Code. Both options lead to false counterfactuals. The goal of the present section is to defend the first premise of my argument against Context Realism. That is, I need to show why it is the case that if Context Realism were true, these and similar counterfactuals would be true. 
I begin by making some general points about properties that are, in a certain sense, objectively real and properties that are, in a certain sense, constructed. There are familiar dangers involved in using the all-too-familiar terms 'objective', 'real', and 'constructed'. However, I use these terms to mark a particular distinction that I think is intuitive. As a rough indication of what I have in mind, compare the property of holding a potato with the property of being "it" in a game of tag. The property of holding a potato is an example of an objective property that someone can have. It is objective at least in the sense that whether someone is holding a potato doesn't depend on anybody's subjective perspective. One could figure out whether someone is holding a potato simply by inspecting the person and their surroundings.

The property of being "it" in a game of tag is different. Whether a given person has the property depends in part on the perspectives of those playing the game. To make the point evident, imagine a group of children $-\mathrm{A}, \mathrm{B}$, and C-playing tag on a playground. Suppose that B is "it" and, in the course of running around, B tags some other child D. Is D now "it"? It depends on the agreed-upon conventions of the children playing, along with the perspective of D. Perhaps there is a general agreed upon convention that children can enter the game by being tagged even if they hadn't agreed to play at the outset. Perhaps $\mathrm{D}$ doesn't wish to play. In that case, A, B, and C may consider D to be "it", whereas D does not. Relative to one perspective, D is "it". Relative to another, $\mathrm{D}$ is not. There is no perspective-free fact of the matter about whether D is "it". The property of being "it" is not really out there in the world. It is constructed by the mind and projected onto the world.

For ease of exposition, I will use the term features for the objective properties, like the property of holding a potato, and I will use the term roles for the constructed properties, like the property of being "it". In what follows, I will focus on a contrast between a somewhat obviously objective property and a somewhat obviously constructed property in order to help pump intuitions. But what matters in the example is that the constructed property exhibits a kind of dependence that is lacking from the objective property. To help make the dependence apparent, it is worth pointing out that constructed properties, or roles, exhibit a relativity to perspectives that is not found in absolutely objective features. There are two reasons why this relativity is not that apparent in the case of some roles.

The first reason is that there is often one perspective, or a set of coordinated perspectives, that is especially salient, so much so that the relativity drops out in our thought and talk about the role. This is what happens with a normal game of tag, where all of the players are in agreement about the rules and the participants.

The second reason is that roles are often conventionally tied to features, lending judgments about roles a kind of objectivity. For example, the property of 
being "it" in a game of tag is conventionally tethered, as it were, to the property of being tagged: a person becomes "it" in virtue of the fact that they are tagged (by the person that was "it" at the moment of tagging). I imagine that most playground arguments about whether someone is "it" turn, not on whether the person is genuinely a participant in the game, but on whether the person was really tagged. And there typically is an objective fact of the matter whether someone was tagged. So it may seem as though there is an objective fact of the matter whether someone is "it". But this is an illusion due to the tethering of the role to the feature.

In saying that the role of being "it" is tethered to the feature of being tagged, I mean to pick out an 'in virtue of' relation that arises from a convention: to say that one property $A$ is tethered to another property $B$ is to say that, according to some convention, an object has $A$ in virtue of having $B$. Note that, as with any 'in virtue of' relation, a tethered property counterfactually depends on what it is tethered to.

Although the rules of a game don't have the power to make a feature-a property that holds objectively-obtain in virtue of some other property obtaining, the rules are nevertheless capable of creating a similar kind of counterfactual dependence between features and roles. For example, the Rosewater Dish is awarded to the Ladies Singles Champion at Wimbledon. As a result of the tournament conventions, the feature of lifting the Rosewater Dish at the end of the tournament counterfactually depends on the role of being the Ladies Singles Champion. Suppose that Serena defeats Venus in the Championship. Then if Venus had been Champion, she would have lifted the Rosewater Dish. Note that the converse does not obtain: putting aside a backtracking reading, it is false to say that if Venus had lifted the Rosewater Dish, she would have been Champion. One does not become Champion by lifting the Rosewater Dish; one lifts the Dish because one becomes the Champion.

This much I take to be straightforward. What I want to show is that it makes a difference whether the conventions of a game involve a feature, such as the property of being the tallest contestant, or a role, such as the property of counting as the tallest contestant. The difference, I argue, shows up in the patterns of counterfactual dependence that result. Ultimately, the goal is to generalize the point to conventions of language in order to show that Context Realism has implications about which counterfactuals are true.

To compare the conventional use of features and roles, I will present a variation of the classic children's game Hot Potato. In the standard version, contestants stand around in a circle and pass a potato around, as though it were hot, while some music plays in the background. When the music stops, whoever is holding the potato is "out". The object of the game is to be the last contestant remaining. 
The variation is a game that I call Height Potato. In Height Potato, the contestants stand in a circle. A neutral referee picks up one of two potatoes-either a red potato and a yellow potato-and places it into the hands of a contestant according to the following rules. If the red potato is chosen, it is to be handed to the tallest contestant. If the yellow potato is chosen, it is to be handed to the shortest contestant. Once the potato is handed to a contestant, the game is over.

Height Potato is not as fun as Hot Potato, but it is useful for making points about counterfactual dependence. The rules of Height Potato are such that who holds a potato counterfactually depends on both the choice of potato and the relative heights of the contestants. Suppose that $A, B$, and $C$ are playing Height Potato, that $A$ is the tallest and $B$ the shortest, and that the referee places the red potato in A's hands. Two counterfactuals are true of this situation. First, if B had been taller than A, B would have held a potato. Second, if the referee had chosen to use the yellow potato, B would have held a potato.

With a bit of generous imagination, we can suppose that this game gets passed down through generations. Over time, children have adapted the gamecall it Modified Height Potato-so that the red and yellow potatoes are handed out randomly, in order to determine who performs certain tasks. Whoever receives the red potato is "tallest" and whoever receives the yellow potato is "shortest". The "tallest" contestant-that is, the contestant that counts as tallest-is in charge of grabbing items from the top shelf of the pantry. The "shortest" contestant is in charge of crawling under the sofa to look for loose change. In other words, the potatoes function to assign roles to the contestants, roles which might then serve some other purpose.

That there is a difference between actually being the tallest contestant and counting as the tallest is clear enough. A child might receive the red potato, and thus be in charge of retrieving items from the top shelf of the pantry, even though the child is not the tallest in the group. What matters for my purposes is the effect that this difference has on the truth-values of certain counterfactuals.

In the original version of Height Potato, the property of holding a red potato counterfactually depends on the property of being the tallest contestant. In the modified version of the game, the property of counting as the tallest contestant counterfactually depends on the property of holding a red potato: the role is tethered to the feature.

To see this, imagine once again that $A, B$, and $C$ are playing one of the two games. $\mathrm{A}$ is the tallest, $\mathrm{B}$ is the shortest, and the referee places the red potato in A's hands. Is it the case that if B had been taller than A, B would have held a potato? It depends on whether they are playing Height Potato or Modified Height Potato. That is, it depends on whether the potato is linked to the objective relative heights of the contestants, or whether it is linked to the role of counting as the tallest. The counterfactual is only true if the use of the potato is defined 
in terms of the objective relative heights-a feature of the situation.

Similarly, is it the case that if the referee had used the yellow potato, B would have held a potato? Again, it depends on whether they are playing Height Potato or Modified Height Potato. The counterfactual is only true if the yellow potato is associated with the feature of being the shortest contestant. It is either false or of indeterminate truth-value if the yellow potato is associated with the role of counting as the shortest. The role counterfactually depends on who holds the potato, and not the other way around.

The result generalizes to indexicals. The choice to use 'my' or 'your' is analogous to the referee's choice to use the red or yellow potato. The question is whether ' $m y^{\prime}$ and 'your' are defined in terms of objective features of utterance situations (being the speaker, being the addressee) or constructed roles (counting as the speaker, counting as the addressee). According to Context Realism, 'my' and 'your' are defined in terms of objective features-features which obtain independently of the interpretation of the indexicals. We can characterize the key implications of Context Realism-key for establishing the first premise of my argument against it-in terms of a claim about independence and a claim about dependence:

Independence: The feature that fixes the referent of an indexical is borne by the referent independently of the interpretation of that indexical.

Dependence: What a use of an indexical picks out counterfactually depends on what has the feature associated with the indexical.

Note that both of these claims have analogues that are true for the relevant properties in Height Potato, and false for the relevant properties in Modified Height Potato. The point in drawing the analogy is to illustrate the source of these two claims. They arise, not from any aspect specific to indexicality, but rather from the fact that, according to Context Realism, indexicals involve the conventional linking of a property-in this case, the property of using a particular indexicalto a feature and not to a role.

To see how these claims imply the truth of certain counterfactuals, it will help to assume that we are dealing with a situation in which there is a distinct speaker and addressee, analogous to a normal game of Height Potato. More generally, I will call a situation normal just in case the situation involves utterance features that fall along a particular dimension-either person, time, day, location, or object-and that are instantiated by distinct objects. In other words, a normal situation is one in which the speaker is distinct from the addressee, the present day is distinct from the day after the present day, and so forth. I will call a plurality of indexicals complementary just in case each indexical in the plurality corresponds to a different feature along a particular dimension. So, for example, 
'today', 'yesterday' and 'tomorrow' are complementary, as are 'this' and 'that', 'here' and 'there', and ' $\mathrm{I}$ ', 'you', 'he' and 'she'. In stating my defense of the second premise, I will focus on the complementary pair 'my' and 'your'.

Suppose that Context Realism is true, and suppose that there is an utterance of ' $m y^{\prime}$ in a normal situation. By definition, there is a distinct speaker and addressee. Call the speaker ' $A$ ' and call the addressee ' $B$ '. By Independence, the fact that $A$ is the speaker is independent of the interpretation of ' $m y$ '. Likewise, the fact that B is the addressee is independent of the interpretation of 'your'. In other words, if the expression uttered by A had had a different meaning, A would nevertheless still be the speaker. By Dependence, together with our assumption that 'your' picks out the addressee, the referent of 'your' counterfactually depends on who the addressee is. It follows from these two claims that if 'your' had been used, it would have picked out B. Similarly, if we imagine that 'your' is used to pick out B, Context Realism implies that if ' $m y^{\prime}$ had been used, it would have picked out $A$.

Generalizing from the details of the example, anytime that an indexical is used in a normal situation where there is a complementary indexical that could have been used, Context Realism implies that if the complementary indexical had been used, it would have referred to something other than what the indexical actually used referred to. And it is to this general claim that the Zip Code entry scenario provides a counterexample.

Here is another way of understanding the import of the first premise. If Context Realism is true, then we should never have a choice about which among some complementary set of indexicals we use to express a particular proposition in a normal situation. But we do have a choice in the Zip Code entry scenario. I can use 'My Zip Code' or 'Your Zip Code' to pick out myself, and in each case the complementary indexical picks out the reader of the site. The very existence of such a choice likens the situation to that of the referee in Modified Height Potato. If the referee chooses the red potato, the recipient counts as the tallest. If yellow, the recipient counts as the shortest. Likewise, if I choose 'my', I count as the speaker. If I choose 'your', I count as the addressee. According to Context Realism, such a choice should be impossible.

This concludes my argument against Context Realism. Still, there is more to be said. For example, if indexicals are defined in terms of roles, what explains the situations in which we cannot choose which indexical to use? A defense of Context Constructivism requires an answer to that question. Before moving on to defend Context Constructivism, I pause to briefly consider some likely responses to my argument against Context Realism. 


\section{Stalnaker's Gambit, and Other Responses}

To help clarify my argument, I begin with an objection that relies on a move that I call Stalnaker's Gambit. Stalnaker's Gambit is a type of move made to explain a difference in interpretation in terms of a difference in the utterance situation. Specifically, the move is to identify the relevant difference in situation in terms of a difference in the linguistic expression used. ${ }^{6}$ According to this strategy, the situation in which I use 'Your Zip Code' is different from the situation in which I use 'My Zip Code'. So it doesn't follow that if I had used one expression in place of another, the semantically relevant contextual facts would stay the same. Shifting the expression used thereby shifts the context with respect to which it is interpreted. Thus, the objection goes, the first premise of my argument fails.

I grant that the situation in which I use 'My Zip Code' is different from the situation in which I use 'Your Zip Code'. However, the question is whether this difference can be semantically relevant according to a Realist conception of the context. If the only difference between the expressions had been orthographic-if we replaced ' $m y^{\prime}$ with a synonymous word that is spelled differently-the interpretation would be the same. The relevant difference between the expressionsthe only difference that could be responsible for a shift in interpretation-is the semantic difference, their different characters.

But why would the character of an expression affect which objects have which properties? The only plausible story concerns the particular interpretation that would result from the character. However, in virtue of the Independence claim, a Realist cannot hold that it is because of the resulting interpretation that the character has a semantically relevant effect on the context. If an object has a particular feature independent of the indexical used, then it should not matter which indexical gets used, as far as that feature is concerned. Stalnaker's Gambit is, therefore, declined. ${ }^{7}$

Still, there are strategies open to the Realist to resist my argument. One strategy is to deny that the Zip Code entry scenario is somehow abnormal in a general sense that precludes it from mattering for the purposes of developing a semantics of indexicals. In the narrow sense defined above, a normal situation is one in which there is a distinct speaker and addressee. And the Zip Code entry scenario, on any interpretation of the indexicals, seems to be normal in that

6. For an example of the strategy, see Section 4 of Stalnaker 1998). In naming the strategy, I do not mean to suggest that Stalnaker himself would raise this objection to my argument.

7. It is worth noting an additional problem with appealing to Stalnaker's Gambit, from a Kaplanian perspective. Such an appeal is at odds with a key feature of Kaplan's approach, namely the ability to "mix and match" contexts and indexicals. In other words, if we adopt Stalnaker's Gambit, we sacrifice the ability to consider the interpretation of various indexicals relative to the same context, a sacrifice that many Kaplanians may be unwilling to make. I thank an anonymous referee for pointing out this consequence. 
sense. However, the scenario is significantly different from a normal face-to-face conversation. So much so, perhaps, that we can safely ignore it.

The danger in trying to find some ground for excluding this scenario lies with how much else falls with it. Many ordinary uses of the first person pronounones in which there seems to be a "correct" interpretation-do not involve a person physically uttering the words. Indeed, such cases have motivated a retreat from talking about the speaker of the context to talking, more abstractly, about the agent of the context. ${ }^{8}$ So the mere fact that the situation is not a face-to-face conversation does not immediately present grounds for excluding it from the relevant data.

Furthermore, in what follows, I consider other situations that result in the same phenomenon of indexical choice, but which do not involve technology or written speech. What motivates Realism more than anything else are the clear intuitions about how indexicals are to be interpreted in particular situations. And the Zip Code entry scenario is not significantly different from many other uses of indexicals in this regard. In other words, in considering the scenario, we know how we are supposed to interpret the indexical; it is not as though its interpretation is completely up for grabs. If we throw out this case, we need to throw out a large number of other cases in which Realism is thought to provide an explanation for the interpretation of indexicals.

Other potential Realist responses can be found in the literature concerning the so-called Answering Machine Puzzle. ${ }^{9}$ In short, the puzzle is to explain how it is that ' $\mathrm{I}$ am not here now' can be uttered truly on an answering machine recording. A number of explanations have emerged.

One approach is to invoke deferred utterances, utterances which occur at a time later than their production. ${ }^{10}$ This approach is plausible in cases where the contextual features of the utterance production are relevantly different from those of the utterance assessment. However, even if we treat the creating of a website as a kind of deferred utterance, the differences between the situation in which the website is created and that in which it is assessed do not help to explain why both the creator and the assessor can count as the speaker and as the addressee at a single time of assessment. In other words, merely invoking deferred utterances will not explain the puzzle of indexical choice.

Another approach is to identify a context other than the context of utterance that is responsible for fixing the reference of the indexical. Stefano Predelli, for example, argues that it is the context intended by the speaker that fixes the reference of indexicals. Komarine Romdenh-Romluc argues that it is the context that

8. See, for example, Soames (2002).

9. See Sidelle (1991) for a clear statement of the puzzle, and see Cohen (2013) and Michaelson (2014) for more recent work on it.

10. See Sidelle (1991), Cohen 2013), and Egan 2009) for this sort of approach. 
the intended audience would recognize. ${ }^{11}$ Both of these views aim to introduce enough flexibility in order to account for the range of problematic cases facing more traditional approaches to indexicals. Predelli's view is well-suited to explain the situations in which we can choose which indexical to use, though it runs into problems explaining those situations in which it seems that we cannot so choose. Romdenh-Romluc's view introduces more constraints.

Regardless of issues concerning the descriptive adequacy of these proposals, both views face a deeper problem. Insofar as they are designed to explain which interpretation of an indexical is the "correct" one, both proposals get the order of explanation backwards. We figure out which interpretation must have been intended by the speaker and which would have been recognized by the audience by figuring out how to interpret the indexical. Cohen argues that both proposals suffer from relying on too much subjectivity (Cohen, 2013, 26). I believe he is mistaken: both views suffer from holding on to the assumption of Context Realism.

A final response on behalf of the Realist is to concede that 'my' and 'your' in the Zip Code entry scenario are defined in terms of roles, but to deny that all uses of 'my' and 'your' are defined in terms of roles. Perhaps 'my' is ambiguous between an indexical that picks out the speaker and one that picks out whoever counts as the speaker. Or perhaps 'my' has a constant character that zeros in on different features in different sorts of situation. For example, as Eliot Michaelson has argued, in a face-to-face setting, 'my' picks out whoever is speaking. On an answering machine, 'my' picks out whoever owns the telephone line. On a postcard, 'my' picks out the author of the card. ${ }^{12}$ Perhaps on a website 'my' picks out whoever counts as the speaker.

While I find this sort of view tempting, I have some misgivings about the overall approach. The explanatory adequacy of the shifty approach requires a specification of the types of contexts in which each rule gets applied. Unless all non-face-to-face situations are grouped together, I am skeptical that the project of dividing utterance situations into distinct types will ultimately provide the correct explanation of the range of possible interpretations of indexicals. And if we do suppose that all non-face-to-face situations invoke a role-defined indexical, then a Constructivist theory that can also explain face-to-face communication has the advantage of providing a univocal account of indexicals, without any shiftiness.

More importantly, the pattern of occasional indexical choice exhibited by 'my'

11. See, for example, Predelli (2005) and Romdenh-Romluc (2006). Cohen (2013) provides a useful discussion of both of these proposals.

12. See Corazza, Fish, and Gorvett (2002) and Michaelson (2014) for views of this sort. Although the characters discussed in these papers only involve features, they could be easily adapted to invoke roles. It is worth noting that the sort of examples that are used to motivate these theories do not involve indexical choice. 
and 'your' is also exhibited by other complementary pairs of indexicals in situations that involve no special technology or written language. For example, 'here' and 'there' and 'this' and 'that' exhibit similar patterns of usage. In some cases, one can choose which indexical to use. In others, no such choice exists. Invoking shifty characters defined in terms of different types of utterance situations cannot explain the general pattern. In the next section, I argue that Constructivism can explain the general pattern.

\section{Role Casting}

In the event that one wants to express a particular proposition, some utterance situations permit a choice among complementary indexicals, while other situations do not. What explains when one can choose and when one cannot?

In order to see how Context Constructivism has the resources to answer this question, it is important to recognize a disanalogy between using indexicals and playing Modified Height Potato. When we play Modified Height Potato, the goal is simply to assign individuals to particular roles. There need not be any further goal constraining how the assignments are made. When we use indexicals, the goal is not simply to assign individuals to particular roles; the goal is to do so in a way that facilitates communication of some piece of information, or of some question or command.

With this additional cooperative goal in play, we should expect certain broadly Gricean principles to apply to our choice of assignments. And indeed, that is what we find. In this section, I characterize Gricean principles that arise from a Constructivist approach to context and which introduce constraints on how we use indexicals. Crucially, the constraints are not constraints on reference. Rather, they are constraints on interpretability. That is, what gets constrained is not the "correct" interpretation of the indexical; rather, it is the ability of those interpreting the indexical-the conversational participants-to coordinate their interpretations. Ultimately, I argue, we can explain our intuitions about when we can and when we cannot choose which indexical to use to refer to something in terms of these constraints on interpretability.

To clarify this idea of constraints on interpretability, it will help to look at an analogy in which similar constraints arise when editing multiple shots of a film together to form a coherent scene. When multiple shots are edited together, there is typically a jump in the camera position and angle between each shot, which could threaten the viewer's ability to follow what's happening in the scene. For example, suppose that we are filming two people talking to each other. In order to preserve the left-right relationship of the characters on the screen, the different camera shots must all take place on one side of the action, so to speak.

There is a well-known principle of film editing, called the 180 Degree Rule, 
which makes the idea more precise. ${ }^{13}$ Imagine a line - call it the "line of action" connecting our two characters and extending just past each of them, along with two 180 Degree arcs that connect the endpoints of the line on either side of the line of action, forming a circle around the characters. According to the 180 Degree Rule, the camera can be placed anywhere along either one of the arcs, but it cannot cross the line of action.

The subtleties of the principle do not matter here. What matters is its general aim. What is the principle aiming to preserve? What do violations of the principle affect? In general, when we watch a scene with multiple key elements-like two characters interacting-we watch it from some perspective. If the perspective shifts in certain ways-for example, if the left-right relationship of the elements is reversed-then it may be difficult for the viewer to keep track of what is happening where. Importantly, violations of the 180 Degree Rule do not affect or determine what is depicted in the scene. Violations only affect the viewer's ability to follow what's depicted in the scene.

Notice that in the case of the 180 Degree Rule, the existence of interpretability constraints results in a pattern of choice and the absence of choice analogous to what we find with indexicals. When filming a scene in which two people are talking to each other, the director can place the camera on either side of them. But once a choice is made-once a perspective is adopted-it constrains which other choices can be made while preserving the viewer's ability to interpret the shots depicting the scene.

The constraints that arise when using indexicals are similar. I argue that they affect, not the content of the indexical, but rather the interpreter's ability to figure out how the indexical is being used-which objects the speaker intends to play which roles. The specific constraints revolve around two concepts, which I call fitness and establishment. These two concepts are not specific to indexicals; rather, they pertain to any use of roles in which coordination of role-assignments is required. To show how the concepts work, I begin with a brief primer about how to cast a play.

Every year, my department puts on a play in order to raise money for the spring reception. This year, we are putting on the hit musical The King and I. To cast the play, we assemble all of the graduate students in a room, and we have a sheet of paper with all of the roles that need to be filled.

Some of the actors fit certain roles particularly well. The very tall and imposing graduate student with the shaved head would be perfect as the King. In fact, if he walked out onto the stage, the audience would probably just assume that he is playing the King without any further indications.

In addition to the graduate students that we could easily type-cast, there are graduate students that don't fit any of the roles any more than anyone else, but

13. The principle is discussed in many books on film editing. See, for example, Katz (1991). 
who could easily play those roles. So we assign students to those roles and then, during the play, the actors establish to the audience which roles they are playing. They do this by wearing indicative costumes, announcing their characters' names, or describing their occupations.

And that is how you cast a play. There are roles and there are actors. Some actors fit certain roles well, such that no additional indication is required for the audience to match the role with the actor. Others could play certain roles, but it needs to be established to the audience that they have been assigned to the role.

On the Constructivist proposal developed here, interpreting an indexical is analogous to casting a play. When an indexical is used, the role associated with it needs to be filled in order for one to interpret the utterance. Among the objects in the world that could be assigned to the role, one or more of them may fit the role especially well. Others may be suitable assignments to the role, without fitting the role better than other objects. In order for interpreters to understand that such an object is intended to play the role, some means of establishing that fact is needed. Before presenting the specific Gricean principles that give rise to constraints on interpretability, some further notes about the concepts of fitness and establishment are in order. I begin with establishment.

Establishment is a kind of metalinguistic act that connects the indexical to the object playing the associated role. Any kind of cue that links an indexical with an object counts as establishment. The use of eye glances, demonstrations, and definite descriptions (for example: "That object—the red one on the left-is about to fall") all count as forms of establishment. Although the generality of the notion may seem to weaken its explanatory force, it is the generality of the notion that helps to explain why it is that we sometimes accompany uses of indexicals with demonstrations, sometimes with eye glances, and sometimes with indicative accompanying text. In other words, it is typically not going to be the case that an eye glance is necessary for a particular utterance of an indexical to be interpreted properly. What is more likely to be the case is that some establishment-some means of indicating which object is intended to play a particular role-is necessary, whether it be an eye glance, a demonstration, or something else.

Whereas establishment is something that a speaker does, fitness is something that an object of reference has. Like physical fitness, it is a matter of degree. Unlike physical fitness, it is a relational property: an object may fit one role more than it fits another role. I will not offer a precise theoretical specification of what it is for an object to fit a role to a certain degree. ${ }^{14}$ Insofar as the goal is

14. I note, however, that we could potentially operationalize the concept of fitness in terms of something like expected interpretations in the absence of any establishment. That is, the more an object fits a role, the greater the expectation that a speaker intends to pick out that object with the corresponding indexical. 
to explain how we interpret uses of indexicals, what matters for my purposes is that we have ordinary pre-theoretic intuitions about when an object fits a role, or is well-suited to play a role. The example of casting a play is meant, in part, to illustrate how ordinary the concept is.

However, there are two aspects of fitness worth drawing attention to. The first aspect concerns the roles that an object fits. Like the roles in a play, the roles associated with indexicals do not occur in isolation. They are used in sentences that are part of discourses that occur in conversational settings. These aspects of the broader context in which an indexical use occurs can place demands on a role outside of the narrow definition of the role that is built in to the fixed meaning of the indexical. All of these additional demands can affect which objects fit the role to what degree. For example, if I utter the sentence 'His wife returned home from Barcelona last night,' interpreting the role associated with 'his' requires more than finding someone who counts as a male that is distinct from the speaker and addressee, for the role suggests that the person has a wife who returned from Barcelona. An especially salient male that is distinct from the speaker and addressee, but who is known to be unmarried, will not fit the role particularly well.

The second important aspect of fitness is that it is holistic, in the following sense. Whether one object fits a role depends in part on what other objects are around and which roles they fit. If we are casting a play about two parents and their biological eight-year-old son, then the actors that we cast as the parents will affect which other actors best fit the role of the son. This sort of holism of fitness is due to the relationship that exists between the roles.

Similarly, as a result of the relationship between the roles of complementary indexicals, assigning one object to a role can affect how another object fits another role. For example, consider the complementary indexicals 'today', 'yesterday' and 'tomorrow'. Let us call the role associated with 'today' the PRESENT DAY role, and the roles associated with 'yesterday' and 'tomorrow' the DAY BEFORE PRESENT and the DAY AFTER PRESENT roles respectively. ${ }^{15}$ Now imagine a situation in which a person in the late stages of life records a video will. Let us suppose that the person decides to be euthanized on Monday, the same day that the video will is recorded. The person gives instructions to the lawyer in charge of the estate to show the video to family members in the lawyer's office the following day. Here are four different ways that the video might begin:

(1) Today I awoke for the last time in my life.

(2) Yesterday I awoke for the last time in my life.

15. I will henceforth use small caps to pick out roles, as opposed to features. 
(3) Today you all received a phone call telling you to come to my lawyer's office.

(4) Tomorrow you will all receive a phone call telling you to come to my lawyer's office.

Like the Zip Code entry scenario with which this paper began, the speaker has a choice about which indexical to use. In (1) and (2), 'today' and 'yesterday' are used to pick out Monday. In (3) and (4), 'today' and 'tomorrow' are used to pick out Tuesday. (This is not to say that these are the only possible interpretations, but simply that they are the intended ones.)

What difference does it make whether 'today' or 'yesterday' is used to refer to Monday? Once Monday is assigned to the PRESENT DAY role, it affects which other days fit which roles. For example, it increases the fit between Tuesday and the DAY AFTER PRESENT role. We can test this claim by comparing the videos that begin with (1) and (2) respectively, under the supposition that they both continue with (5):

(5) My last request is that you raise a glass in my honor tomorrow at $5 \mathrm{pm}$.

The question is: on what day will the dutiful family members who watch the video raise a glass? I claim that if the video begins with (1), they are more likely to raise the glass on Tuesday, the day they watch the video. If the video begins with (2), they are more likely to raise the glass on Wednesday, the day after they watch the video.

We can think of the relationship between complementary indexicals in terms of how one frames one's environment. A frame is a way of conceiving of one's environment along some particular dimension, a perspective one can adopt. ${ }^{16}$ For example, one can cognitively carve up one's environment into proximal and distal regions, or into past, present, and future regions. And there can be a great deal of freedom in how this is done. ${ }^{17}$

For example, if I am seated at one end of a long dinner table, and if a salad bowl is set down on my half of the table, I could frame the salad bowl as being proximal to me or as being distal to me. It is as if I can draw, with my mind's eye, a line dividing the region of space that I occupy. Using the phrase 'this salad bowl' includes the salad bowl inside the proximal region; using 'that salad bowl' treats the bowl as distal. Where I draw the line is up to me. But if I

16. For a more detailed and more general account of frames, see Goffman (1974), Chapter 13 of which concerns the use of frames in analyzing speech, including the use of indexicals.

17. Michael Silverstein (1976), a linguistic anthropologist, makes a similar point, albeit from a very different theoretical framework. See his discussion of "creative indexicality". Note that, unlike the approach presented here, Silverstein thinks of this creativity as a built-in feature of some, but not all, indexical expressions. 
hope to be interpreted correctly, I ought to draw it in a natural location. If a second salad bowl is set down on the other half of the table, then that affects the fitness of the closer salad bowl to the PROXIMAL OBJEcT role associated with 'this'. The increase in fitness doesn't preclude me from using 'that' to refer to the closer salad bowl; it simply makes it more likely that I will be misinterpreted. To avoid misinterpretation, I would need to employ some additional establishment (for example, a pointing gesture) that would make it clear to which salad bowl I intended to refer. ${ }^{18}$

Generalizing from this example, we can formulate several pragmatic principles that concern the relationship between fitness and establishment whenever there is a need to coordinate role assignments. Here are three such principles:

Proportion: The better an intended object of reference fits a role, the less establishment that is needed to be correctly interpreted.

Plurality: When more than one object fits a role to a similar degree, some establishment is required to distinguish the intended referent in order to be correctly interpreted.

Uniqueness: When only one object fits a given role to a significant degree, no additional establishment is required to be correctly interpreted.

I leave it open whether we can define some of these principles in terms of others. All three are concerned with how much establishment is required, given the distribution of fitness among referential candidates, in order for the speaker to be understood. The principles emerge from the fact that the coordination of role assignments between speaker and hearer requires cooperation, much like Grice's maxims.

As these principles illustrate, the distribution of fitness among referential candidates-which objects fit which roles to which degrees-constrains the interpretable framings. It is in terms of the framing constraints that we can, at last, answer the question with which this section began: what explains when we can and when we cannot choose which of a set of complementary indexicals to use to refer to some object?

18. See Elbourne (2008) for a semantic account of 'this' and 'that' in terms of a proximal/distal distinction. A similar story can, I think, be told about 'here' and 'there', in terms of PROXIMAL LOCATION and DISTAL LOCATION roles. Though it seems to be taken for granted in the linguistic anthropology literature (stemming largely from the work of Silverstein) that 'here' and 'there' function semantically as a proximal/distal pair, the philosophical literature on indexicals (stemming largely from the work of Kaplan) have traditionally treated 'here' and 'there' as semantically unrelated. For some notable exceptions, see Bezuidenhout (2005), Récanati (2001), and Rundle (1983), the last of which is cited in Predelli (2013, 86, footnote 14) for "intriguingly" accounting for 'here' and 'there' as analogous to 'this' and 'that'. 
Choice: When the distribution of fitness permits alternative interpretable framings using a set of complementary indexicals, then one can choose which indexical to use to refer to a given object.

Restraint: When the distribution of fitness permits only one interpretable framing, then one cannot choose which indexical to use.

To say that a distribution of fitness permits alternative framings is to say that a given collection of one or more objects fit multiple complementary roles to a more or less equivalent degree. Utterance situations that satisfy the Choice condition are rarer for indexicals like ' $\mathrm{I}$ ' and 'today', but more common for indexicals like 'there' and 'that'. The opposite is true for the Restraint condition. I suspect that this difference-a difference in degree and not in kind-is responsible for the intuition-mistaken, on my view-that there is some fundamental semantic cleavage between the so-called "pure" and "impure" indexicals.

Note that, whereas indexical choice is a matter of fitness, the interpretation of an indexical-once a choice is made-is a matter of fitness and establishment. This is not to say that fitness and establishment together determine how an indexical is interpreted. An interpreter may rely on background knowledge about the speaker, or a gut instinct, if not enough clues have been given.

Returning to the Zip Code entry example, we can now explain why it is that the 'my' in My Zip Code could be replaced with 'your' while preserving the intended reference, whereas the 'my' in Please enter my Zip Code could not be so replaced. At each stage of a typical two-person face-to-face conversation, there is a one-to-one correspondence between people and the roles they fit (at least, with respect to the SPEAKER and ADDRESSEE roles). But on websites, where the production and reception of words are mediated by a screen, the abstractness of the situation results in mutual fitness of the SPEAKER and ADDRESSEE roles. As a result, framing the reader of the site as the SPEAKER or as the ADDRESSEE is interpretable. The fact that the phrase appears next to a box in which the reader is supposed to enter a Zip Code establishes that the indexical is used to pick out whomever's Zip Code is intended to be entered.

Note that a similar explanation is not available when Please enter my Zip Code is used. Because of the imperative mood of the sentence, a command is issued from the SPEAKER to the ADDRESSEE. This affects the respective fitness between the reader and the producer of the website with respect to the two operative roles. Since a command comes from a source and is direct toward a target, the source of the command naturally fits the SPEAKER role. More importantly, since the viewer of the website is the only one capable of entering a Zip Code, the viewer is the natural target of the command, thus ruling out a framing of the situation where the viewer plays the SPEAKER role. 
To be clear, I am claiming that the constraints introduced by fitness and establishment are constraints, not on the content of the indexical, but on the ability for participants to coordinate their interpretations of the indexical. This is in contrast to more traditional views according to which there is some correct interpretation that is determined or constrained by the meaning of the indexical together with the utterance situation. By appealing to interpretability constraints and eschewing the Realist idea of a correct interpretation, we can explain when we can and when we cannot choose which indexical among a complementary set to use. The inability to choose, on this approach, is an inability to use an indexical in a way that others will follow. This account may strike many readers as overly permissive. I conclude the paper with a brief defense of the permissiveness of Constructivism.

\section{Coordination and Correctness}

I have argued that only a Constructivist approach to context can adequately solve the puzzle about indexical choice. According to Constructivism, while indexicals do have a content relative to a context (substitute "index" if you prefer), contexts are not the sorts of things that are fixed independently of the interpretation of an indexical. The context just is the assignment of objects to roles associated with each indexical uttered. Interpreting the indexical just is constructing a context.

In any utterance situation, the various conversational participants might disagree about how to interpret the utterance. According to Constructivism, there is no objective fact of the matter about which one of these interpretations is the correct one. Of course, there may be a fact of the matter about which interpretation is intended by the speaker, or which would be most natural. But Constructivism allows this much. The idea is that nothing more is gained by selecting some one context as the "real" one. ${ }^{19}$ This approach is closely related to what Kaplan has called subjectivist semantics, a view he characterizes as follows:

When we speak, we assign meanings to our words; the words themselves do not have meanings. These assignments are, in theory, unconstrained (except by whatever limitations our epistemic situation places on what we can apprehend). In practice, it may be prudent to try to coordinate with the meanings others have assigned, but this is only a practical matter. (Kaplan, 1989b, 600)

What is up to each of us, I have argued, is the context with respect to which an indexical is interpreted. Of course, this claim flies in the face of the idea that a use of ' $\mathrm{I}$ ' means what it does, regardless of what anybody thinks it means. Still,

19. See Heck 2002, 31-32) and Heck (2014) for a related point. 
despite the permissiveness of Constructivism, I believe that our intuitions about the correctness of interpretations are not difficult to account for.

Language use has both an intentional and a social component. Performing a speech act is something that an individual does. But the performance is made socially, against the background of certain conventions and constraints. When everything goes well-when the conversational participants all coordinate their interpretations around the most natural interpretation-there is no harm in speaking of the content of the speech act.

It is when things are sub-optimal-when the intentional and social aspects of the speech act come apart-that our intuitions get pushed and pulled. If we insist that these sub-optimal utterances have a single correct interpretation, then we need to find something that fixes the referent of the indexical. We can choose a factor that favors the intentional aspect (like the speaker's intention) or one that favors the social aspect (like salience). The problem is that, for any factor we select, we can find an example where that factor is responsible for the sub-optimality, hence where the predicted content is at odds with the intuitively correct interpretation.

When things are optimal, it is harmless for the Constructivist to talk of "the" content of a speech act; this is much like reporting who is "it" in an uncontentious game of tag. But no explanation is owed by the Constructivist when things are sub-optimal. Utterances need not be associated with any single context. What we need to explain is not which proposition really gets expressed. Rather, we need to explain where the conflicting interpretations come from. We do not need to take the further step of anointing one of the interpretations as correct, for doing so explains nothing. By shifting our focus from reference-fixing to interpretation-influencing, we can avoid the pitfalls of Realism without sacrificing anything of explanatory value.

\section{Acknowledgments}

The main ideas in this paper grew out of my dissertation. I owe a great deal of thanks to my advisors, Gilbert Harman and Jim Pryor, along with my readers, Delia Graff Fara and John Burgess. Thanks go out also to the many, many others who have helped me work through this material over a very long period of time, including Chris Barker, Ray Buchanan, Elaine Chun, Daniel Fogel, Richard Heck, Su Kim, Barry Lam, Mike McGlone, Eliot Michaelson, François Récanati, Daniel Rothschild, Mark Schroeder, Susanna Siegel, Scott Soames, Jason Stanley, Seth Yalcin, three anonymous referees, along with audiences at Auburn University, Brandeis University, Ecole Normale Supérieure, and the University of Rochester. 


\section{References}

Bach, Kent (1992). Intentions and Demonstrations. Analysis, 52(3), 140-146.

Bezuidenhout, Anne (2005). Indexicals and Perspectivals. Facta Philosophica, 7(1), 3-18.

Brandom, Robert (2008). Between Saying and Doing: Towards an Analytic Pragmatism. Oxford University Press.

Cohen, Jonathan (2013). Indexicality and the Puzzle of the Answering Machine. The Journal of Philosophy, 110(1), 5-32.

Corazza, Eros, William Fish, and Jonathan Gorvett (2002). Who is I? Philosophical Studies, 107(1), 1-21.

Egan, Andy (2009). Billboards, Bombs, and Shotgun Weddings. Synthese, 166(2), 251-279.

Elbourne, Paul (2008). Demonstratives as Individual Concepts. Linguistics and Philosophy, 31(4), 409-466.

Fillmore, Charles (1997). Lectures on Deixis. CSLI Publications.

Goffman, Erving (1974). Frame Analysis. Harvard University Press.

Heck, Richard (2002). Do Demonstratives Have Senses? Philosophers' Imprint, 2(2), 1-33.

Heck, Richard (2014). Semantics and Context-Dependence: Towards a Strawsonian Account. In Alexis Burgess and Brett Sherman (Eds.), Metasemantics (327-364). Oxford University Press.

Kaplan, D. (1989a). Demonstratives. In Joseph Almog, John Perry and Harold Wettstein (Eds.), Themes From Kaplan (481-563). Oxford University Press.

Kaplan, D. (1989b). Afterthoughts. In Joseph Almog, John Perry and Harold Wettstein (Eds.), Themes From Kaplan (565-614). Oxford University Press.

Katz, Steven (1991). Film Directing Shot By Shot: Visualizing from Concept to Screen. Michael Wiese Productions.

Lewis, David (1980). Index, Context, and Content. In Stig Kanger and Sven Öhmen (Eds.), Philosophy and Grammar (79-10o). Reidel Publishing Company.

McCawley, James (1999). Participant Roles, Frames, and Speech Acts. Linguistics and Philosophy, 22(6), 595-619.

Michaelson, Eliot (2014). Shifty Characters. Philosophical Studies, 167(3), 519-540.

Murray, Sarah (2014). Varieties of Update. Semantics E Pragmatics, 7(2), 1-53.

Perry, John (1997). Indexicals and Demonstratives. In Bob Hale and Crispin Wright (Eds.), A Companion to the Philosophy of Language (586-612). Blackwell Publishing.

Perry, John (2006). Using Indexicals. In Michael Devitt and Richard Hanley (Eds.), The Blackwell Guide to the Philosophy of Language (314-334). Blackwell Publishing.

Predelli, Stefano (2005). Contexts. Oxford University Press. 
Predelli, Stefano (2013). Meaning without Truth. Oxford University Press.

Récanati, François (2001). Are 'Here' and 'Now' Indexicals? Texte, 127(8), 115125.

Récanati, François (in press). From Meaning to Content. In Derek Ball and Brian Rabern (Eds.), The Science of Meaning. Oxford University Press.

Romdenh-Romluc, Komarine (2006). 'I'. Philosophical Studies, 128(2), 257-283.

Roberts, Craige (2012). Information Structure: Towards an Integrated Formal Theory of Pragmatics. Semantics and Pragmatics, 5(6), 1-69.

Rundle, Bede (1983). Conjunctions: Meaning, Truth, and Tone. Mind, 92(367), 386-406.

Sidelle, Alan (1991). The Answering Machine Paradox. Canadian Journal of Philosophy, 21(4), 525-539.

Silverstein, Michael (1976). Shifters, Linguistic Categories, and Cultural Description. In Keith Basso and Henry Selby (Eds.), Meaning in Anthropology (11-55). University of New Mexico Press.

Soames, Scott (2002). Beyond Rigidity: The Unfinished Semantic Agenda of Naming and Necessity. Oxford University Press.

Stalnaker, Robert (1998). On the Representation of Context. Journal of Logic, Language, and Information, 7(1), 3-19. 